\title{
O exercício da crítica: «minha prosa mais áspera»
}

The exercise of criticism: «my roughest prose»

\author{
Ida Alves ${ }^{1}$
}

Resumo: A importância da obra plural de Jorge de Sena (1919-1978) no campo da crítica literária de língua portuguesa. Seu trabalho intenso de crítica dedicada às relações culturais, políticas e literárias luso-brasileiras, a partir da experiência de vida nos dois países ligados pela mesma língua. 0 conceito de cultura definido por uma tríplice exigência: dúvida metódica, juízo analítico, visão sintética a par de um método de análise que consistia em penetrante dialética interpretativa.

Palavras-Chaves: Jorge de Sena; literatura portuguesa moderna; crítica de poesia; relações luso-brasileiras.

\begin{abstract}
The importance of the plural work of Jorge de Sena (1919-1978) in the field of Portuguese literary criticism. His intense work of critique dedicated to Portuguese-Brazilian cultural, political and literary relations, based on the life experience in the two countries connected by the same language. The concept of culture defined by a threefold requirement: methodical doubt, analytical judgment, synthetic vision along with a method of analysis that consisted of a penetrating interpretive dialectics.
\end{abstract}

Keywords: Jorge de Sena; modern Portuguese literature; poetry criticism; Portuguese-Brazilian relations.

\footnotetext{
${ }^{1}$ Instituto de Letras, Universidade Federal Fluminense. Professora titular de Literatura Portuguesa no Instituto de Letras da Universidade Federal Fluminense (UFF), Niterói, Rio de Janeiro, Brasil. Pesquisadora do CNPq e da FAPERJ, Brasil. Membro do Polo de Pesquisas Luso-Brasileiras (PPLB), sediado no Real Gabinete Português de Leitura, Rio de Janeiro.
} 
Não sei o lugar que Jorge de Sena ocupa nas letras portuguesas, nem isso é questão que me preocupe. Sei, sim, o lugar que ele ocupa no meu espírito e no meu coração; isso me basta. E aí, o lugar dele, há já longos anos, é muito alto. Reconhecer em Jorge de Sena um dos homens mais lúcidos e inquietos e brilhantes do nosso tempo - como já tem sido dito - é uma maneira cómoda de arrumar alguém que escolheu a incomodidade, sem nenhuma inocência ou ilusão, como modo de existir e pensar por conta própria.

(Andrade, 1992: 1946)

Eu invejo sinceramente os escritores-turistas, aqueles que são capazes de visitar um país que nunca viram e de que quase nunca ouviram senão generalidades, cuja língua não falam, cuja população não contactam, de cujos problemas não inquirem, e que, no entanto, regressados de uma estadia de quinze dias nos hotéis de luxo -iguais em todo o mundo, e com o mesmo «pudim caramel» - e de vários sobrevoos por entre as nuvens que cobrem um país de escala continental, opinam com a ligeireza encantadora e com deliciosa ou ponderosa irresponsabilidade. E os leitores de boa-fé acreditam.

(Sena, 1988: 95)

Jorge de Sena, com sua escrita muitas vezes áspera, rude, irônica ou apaixonada, foi um poeta e prosador incômodo, provocador e polêmico, com toda consciência de sê-lo inteiramente. Um escritor desmedido a que faltou mais vida para sua obra imensa, colhido que foi pela morte aos 58 anos; um leitor crítico até o fim:

Devo dizer que desesperei totalmente da cultura portuguesa em Portugal e no mundo, e que não invejo a satisfação absurda e ridícula com que portugueses se publicam, se louvam ou se mordem. Ao fim de 34 anos de escrever, 32 de publicar, e quase 12 de ensinar litera- tura, o meu desengano crítico é total - e, se um dia me puder esquecer de que a língua portuguesa existe, com tudo o que ela implica de estupidez e de maldade (o que não quer dizer que as outras não impliquem o mesmo - mas não são de nascença minhas), creio que morrerei em paz. Que vos leve o diabo. (Sena, 1999: 13)

Contra a opinião «ligeira» e «irresponsável», tanto em relação à análise da realidade social de determinado espaço, quanto aos mais diversos aspectos culturais, é que esse escritor português lutou, exercendo uma rigorosa e contínua atividade crítica. Como é bem sabido, por oposição ao regime salazarista em Portugal, exilou-se no Brasil, no período de 1959 a $1965^{2}$, vindo a realizar aí seu projeto há muito acalentado de uma carreira docente em Letras e parte de sua obra, em que se destacam ${ }^{3}$ o livro de poesia Metamorfoses: Seguidas de quatro sonetos a Afrodite Anadiómena (publicado em Lisboa, 1963) e obras críticas como

\footnotetext{
${ }^{2}$ Sobre esse período, anota Eugénio Lisboa (1979): «Tomada a decisão de um exílio voluntário, fixa-se no Brasil, como catedrático contratado de Teoria da Literatura na Faculdade de Filosofia, Ciências e Letras de Assis, no Estado de São Paulo. Dois anos depois, em 1961, mudava-se para a Faculdade de Filosofia, Ciências e Letras de Araraquara, como catedrático contratado de Literatura Portuguesa, cargo de que se virá a licenciar em outubro de 1965, altura em que decide partir para os Estados Unidos, e do qual pedirá a demissão em 1967. Entretanto defendera no Brasil tese de doutoramento em Letras e de livre-docência em Literatura Portuguesa, com o tema: "Os sonetos de Camões e o soneto quinhentista peninsular”. Adquirira também a cidadania brasileira» (p. 14).

${ }^{3}$ Comenta Mécia de Sena: «Cremos poder dizer, sem receio de exagero, que o Brasil proporcionou a Jorge de Sena os seus anos de máxima produtividade» (Sena, 1988: 10).
} 
O poeta é um fingidor e $O$ reino da estupidez I (ambos publicados em 1961, também em Lisboa), para além de diversos e fundamentais estudos sobre a obra camoniana ${ }^{4}$ e sobre as literaturas brasileira e portuguesa, que seriam publicados em livros a partir de 1966, já vivendo nos Estado Unidos. Nesse terceiro espaço de sua vida, onde viria a falecer em 1978 , foi professor visitante e depois professor catedrático do Departamento de Espanhol e Português da Universidade de Wisconsin. Mais tarde, mudou-se para a Universidade da Califórnia (Santa Bárbara), da qual foi também professor catedrático do Departamento de Espanhol e Português.

Frente a esse homem de cultura e intenso analista da cultura de língua portuguesa, com uma obra tão extensa, provocativa e de irretocável valor, a extensão deste artigo é muito curta. Por isso, vamos apenas destacar uma face de seu trabalho crítico dedicado às relações literárias luso-brasileiras, que discutiu

\footnotetext{
${ }^{4}$ Destacamos: Uma canção de Camões (análise estrutural de uma tripla canção camoniana precedida de um estudo sobre a canção petrarquista e sobre as canções e as odes de Camões, envolvendo a questão das apócrifas), 1. a edição em 1966; Os sonetos de Camões e o soneto quinhentista peninsular (as questões de autoria, nas edições da obra lírica até às de Álvares da Cunha e de Faria e Sousa, revistas à luz de um critério estrutural à forma externa e da evolução do soneto quinhentista ibérico, com apêndice sobre as redondilhas em 1595-1598, e sobre as emendas introduzidas pela edição de 1598), 1. edição em 1969; A estrutura de "Os Lusíadas» e outros estudos camonianos e de poesia peninsular do século XVI, 1. a edição em 1970. Aos interessados por essa produção específica, ver o artigo «Podereis roubar-me tudo: Subsídios para uma antologia da presença de Camões na produção literária de Jorge de Sena», de Maurício Matos.
}

agudamente, com a experiência de vida em dois países ligados pela mesma língua e por uma história partilhada ${ }^{5}$, no entanto, tantas vezes tão desconhecidos entre si.

Para além de ter sido um verdadeiro intelectual entre dois mundos ${ }^{6}$, Sena desenvolveu um particular método de análise que consistia em instigante «dialética interpretativa»,jamais satisfeita com os resultados obtidos, jamais acomodada diante das «verdades» dominantes. O seu conceito de cultura definia-se por uma tríplice exigência constante e irrevogável de «dúvida metódica, juízo analítico, visão sintética» (Sena, 1971: 179). Com essa perspectiva, compreende-se como esse escritor português, que se tornou cidadão brasileiro (naturalizado em 1963), realizou estudos importantes sobre a cultura brasileira, os quais continuam praticamente ignorados pelos estudiosos da

\footnotetext{
${ }^{5}$ As relações entre Portugal e Brasil têm merecido diversos estudos de especialistas. Uma relação colonial tensa e uma relação pós-colonial complexa explicam muitas vezes o grande afastamento que há entre os dois países, malgrado as tentativas em campos diversos para maior diálogo e intercâmbio. Sobre isso, seguir a reflexão de Eduardo Lourenço em A nau de Ícaro: Seguido de imagem e miragem da lusofonia. ${ }^{6}$ Sobre Jorge de Sena, escreve Frederik G. Williams (1999): «Jorge de Sena (1919-78) é reconhecido como um dos maiores intelectuais das letras portuguesas. A sua erudição cultural é esmagadora e universal. A sua produção criativa e crítica é vastíssima e abarca diversos géneros: poesia, teatro, conto, novela, romance, ensaio, crítica, biografia, história, tradução, teoria literária, correspondência e diário. Ao todo, incluindo os que saíram postumamente, Sena publicou mais de 100 volumes, sem contar as subsequentes edições ou as traduções da sua obra. Até à data já apareceram traduções em volume em nove línguas, a saber: alemão, castelhano, catalhão, chinês, francês, holandês, inglês, italiano, e sueco» (p. 117).
} 
área. Por isso, é contra o desconhecimento de - ou indiferença à - sua contribuição crítica que devemos levantar nossa voz em seu centenário de nascimento, para recordar como Jorge de Sena vivenciou a realidade brasileira e sobre ela escreveu em diferentes momentos, com a análise arguta de diversos pontos complexos da relação Brasil-Portugal.

O aparato crítico seniano não surgiu no vácuo, e o escritor seria o primeiro a criticar qualquer pretensão de universalidade que escamoteasse sua origem. A obra crítica seniana, assim como sua produção poética (que tem como um de seus objetivos principais transformar o mundo, ${ }^{7}$ compreendendo a poesia como um testemunho da condição humana), foi concomitante ao surgimento, instauração e consolidação da ditadura de Oliveira Salazar em Portugal (1926-1974). Dessa vontade de crítica e resistência a qualquer forma de opressão, emergiu a sua forte dialética interpretativa, marca fundamental de vasta obra em prosa sobre diversos temas estéticos, literários, culturais em torno da língua portuguesa, mas não só, haja vista a reflexão sobre as literaturas clássicas e de línguas inglesa e francesa.

Podemos ver esse tipo de crítica exercitada, por exemplo, na discussão sobre a oficialidade

7 Do prefácio à primeira edição de Poesia I: «É que à poesia, melhor que qualquer outra forma de comunicação, cabe, mais que compreender o mundo, transformá-lo» (Sena, 1986: 25). e a não oficialidade da literatura (Sena, 1971: 174-178). Sena parte do princípio de que «as literaturas são oficiais, se oficializam, ou são oficializadas» (1971: 174). Mas o que o crítico entende em ser oficial? Oficial é tudo o que, em suas palavras, «não põe em causa as aparências da ordem estabelecida, ou que apenas episodicamente as põe,como uma bacanal modesta, a domicílio» (1971: 178). O poeta-crítico considera a coexistência implícita das duas literaturas: a não oficial arranca o ser humano de sua conformidade, de seus padrões estabelecidos, enquanto a oficial significa apenas o mero «sorriso da sociedade». Escritores como Camões, Dante, Shakespeare e Dostoievski são «terríveis, perigosíssimos de contactar, capazes de destruir para sempre nosso repouso e a nossa confiança de vivermos» (1971: 176) e, por isso, os seus escritos foram oficializados e permanecem sendo oficializados pela ideologia que estiver no poder. Essa argumentação mostrar-se-á importante, pois é exatamente o Estado-nação, ao nacionalizar as literaturas, ao se apossar do discurso literário, que impõe a maior das oficializações. A relação literária Brasil e Portugal insere-se nessa problemática, segundo Jorge de Sena.

Como já mencionado, Brasil foi o porto seguro do escritor quando se viu na contingência de se exilar de Portugal, em 1959, devido a algumas atividades clandestinas contra 0 sistema político vigente. Bem antes de sua vinda, não ignorava o poeta português alguns nomes da literatura brasileira e já demons- 
trava grande interesse pelo estudo do modernismo brasileiro. No Brasil, Jorge de Sena torna-se professor universitário de literatura, com a tese Uma canção de Camões (alentado estudo sistemático das canções camonianas), e continua com maior aprofundamento o processo de conhecimento crítico da literatura e da cultura brasileiras. Foi um dos estrangeiros, tal como Otto Maria Carpeaux, Casais Monteiro, Paulo Rónai e alguns mais, que buscaram compreender acuradamente a cultura do outro, o Brasil em que passaram a viver e que amaram. Como eles, não foi e nem podia ser um mero «escritor turista»e, por isso, enfrentou temas menosprezados ou silenciados. No âmbito desses estudos, o seu itinerário crítico foi partir do estudo das relações luso-brasileiras para uma crítica da historiografia oficial da formação da nação brasileira e da participação portuguesa nesse projeto. A produção a esse respeito foi divulgada em livro quando, em 1988, a incansável curadora de sua obra, Mécia de Sena, fez publicar Estudos de cultura e literatura brasileira, com «48 estudos, resenhas ou crônicas que sobre o Brasil ou a propósito do Brasil Jorge de Sena escreveu, e cremos que nada ficou de fora» (p.11).

Como a relação Brasil-Portugal se inscreve na obra crítica de Jorge de Sena? Como o escritor português percebeu a tão aclamada parceria entre os supostos países «irmãos»? Como um castelo de cartas. «As relações culturais luso-brasileiras, descontada a troca de comissões e consagrações académicas, sempre abrilhan- tada pelas filarmónicas jornalísticas, sofrem de um langor muito próximo do desinteresse mútuo» (Sena, 1988: 57). Fora das superficiais e inócuas atividades diplomáticas, não há real contacto entre as duas literaturas, não há verdadeiro e contínuo interesse de compreensão e de pesquisa de suas realidades político-sociais. É oportuno lembrar que, somente 18 anos depois da morte de Jorge de Sena, houve em Lisboa, a 17 de julho de 1996, a reunião de chefes de Estado e de Governo que marcou a criação da Comunidade dos Países de Língua Portuguesa (CPLP), entidade que passou a reunir os países Angola, Brasil, Cabo Verde, Guiné-Bissau, Moçambique, Portugal e São Tomé e Príncipe; em 20 de maio de 2002, após tornar-se independente, Timor-Leste tornou-se o oitavo país membro da comunidade. Todavia, uma comunidade de língua não implica uma comunidade cultural. Sena também discute que literatura não é apenas o uso especializado da língua, mas o espaço privilegiado de construções culturais que se confrontam no texto literário. Assim, brasileiros e portugueses podem estar escrevendo e falando o mesmo idioma, mas não necessariamente o entendem e interpretam da mesma forma. Como nos diz o poeta-crítico, «sempre nas relações internacionais da cultura, ainda quando língua mesma as favoreça, há lacunas estranhas, celebridades de acaso, um misto de atraso e vanguarda sobre o próprio panorama da literatura buscada» (Sena, 1988: 61).

Em seus escritos, Sena constata como, na contemporaneidade, Portugal e sua história 
continuavam ignorados pelos brasileiros. Mais ainda: a construção nacional do Brasil excluiu, por diversos motivos, a herança portuguesa. De Portugal, o Brasil desconhece quase tudo: «o pior de tudo isto é que o Brasil ignora tudo de Portugal. Onde Portugal exactamente seja, é matéria muito vaga para alunos mesmo de universidade. Qual seja a nossa História...» (1988: 96). É claro que o escritor crítico não pretende nem de longe «recolonizar» o Brasil, mesmo que seja no plano das ideias. Ele mesmo explica: «eu vivo no Brasil vai para quatro anos, amo o Brasil, tenho-o percorrido de ponta a ponta, tenho estudado dele e de nós o que não estudara ainda, e não faço parte da colónia portuguesa, mas dos quadros do funcionalismo brasileiro, entre brasileiros» (1988: 97). O analista pretende, sim, discutir a veracidade dos fatos e desmontar as ideologias por trás das «verdades» aceites - para se entender um fenômeno cultural tão complexo como é a literatura. É uma questão de fidelidade - uma das palavras mais caras ao ideário estético e reflexivo de Sena.

As relações entre as literaturas brasileira e portuguesa, enfim, são marcadas por tudo o que não atende os critérios de cultura exigidos por Sena: casualidade, superficialidade e aceitação tácita, bem longe das categorias críticas necessárias: dúvida metódica, juízo analítico e visão sintética. Não formam um conjunto, nem mesmo um conjunto de influências, sendo ocasionais e fortuitos os diálogos entre uma e outra pela barreira de preconceitos, pela falta de interesse, tornando-se ainda mais gritantes as diferenças. Sena, na condição de professor de literatura no Brasil, foi um dos que mais lutou para modificação desse quadro, mas foi, em parte, vã a tentativa. A cultura brasileira subsiste ainda da indiferença a Portugal (com exceção do turismo atualmente).

No ensaio que dedicou a Machado de Assis, Sena ainda foi mais claro sobre a questão da grandeza literária: não são as literaturas nacionais grandiosas por si, mas sim os escritores que são notáveis pela importância literária de sua obra. Segundo seu ponto de vista, Machado de Assis é o primeiro que subverte as tendências oficiais e oficiosas da literatura brasileira de então, de uma literatura exótica e pitoresca (que atendia ao diferencial de mercado em comparação às literaturas européias...), e foi ele quem «longamente pagou criticamente o preço de ter buscado ser "brasileiro" por dentro, quando não mais se the pedia que o fosse por fora» (1988: 328).

O crítico português desenvolve, nos estudos a que se dedicou sobre importantes escritores brasileiros, o confronto entre a existência do grande escritor e a nação mesquinha (ou que se considera mesquinha...). Nas literaturas consideradas periféricas, há sempre duas formas igualmente perniciosas de provincianismo: o ufanismo glorificador, por meio do qual qualquer obra nacional é um grande feito na história da humanidade, e - mais sutil - o derrotismo cosmopolita, em que tudo o que é feito na terra não tem importância, sendo 
só digno de valor o que provém do exterior (ontem França, hoje os EUA...). São duas faces da mesma moeda que a crítica lúcida de Jorge de Sena tenta separar.

Em referência a essa imagem brasileira de contínuos atrasos, o ensaio mais incisivo que Sena escreveu sobre um escritor brasileiro, «Os sertões e a epopéia do século XIX», uma das leituras mais argutas e instigantes da obra de Euclides da Cunha8. Misto de reportagem documentada, obra de arte e panfleto gigantesco, Os sertões do escritor brasileiro, segundo o poeta-crítico português, é uma verdadeira epopéia da luta fratricida no interior do Nordeste Brasileiro, onde a história e a negação da história se confrontaram, em um dos momentos mais sombrios da memória brasileira. A tensão entra a nação mesquinha

${ }^{8}$ Euclides da Cunha (1866-1909) é autor de Os sertões: Campanha de Canudos (1902), sua obra-prima, no qual descreve a campanha de Canudos, em 1897, no nordeste da Bahia, com a reação do governo republicano contra o arraial de Canudos e sua gente, liderada por Antônio Conselheiro. Acompanhando de perto a investida das tropas republicanas (quatro expedições), conseguiu reunir material para, durante cinco anos, elaborar Os sertões, que se divide em três partes: «A terra», «O homem» e «A luta». Nelas, o autor descreve e analisa as características geológicas, botânicas, zoológicas e hidrográficas da região, os costumes e a religiosidade sertaneja, para além dos acontecimentos em torno de Antônio Conselheiro. Para acompanhamento da biografia e bibliografia detalhadas dessa figura literária brasileira,verificar https://euclidesite.com.br/biografia/, onde se afirma que «Os sertões valeram ao autor grande notoriedade e vagas na Academia Brasileira de Letras e no Instituto Histórico e Geográfico Brasileiro». e o grande escritor encontra aí um dos seus melhores exemplos:

Não é dos menores paradoxos da história literária, que as grandes obras tenham sido escritas quando os seus autores achavam que as suas pátrias não mereciam que eles as escrevessem... Provavelmente, não mereciam mesmo, já que, na verdade, elas são sempre, apesar das nossas presunções e suscetibilidades, inferiores aos grandes homens que produzem. Mas acontece que, não obstante isso, eles as escreveram, e é precisamente o que os distingue da chusma inglória dos que achando que não vale a pena fazer nada, cumprem realmente as suas convicções... e não fazem nada. Os grandes escritores pensam que tudo está perdido, mas têm em si mesmos uma confiança última. E essa confiança última com que escrevem as suas obras-primas para nos chicotearem a golpes de palavras, é afinal aquilo que, se os não salva a eles, nos salva a nós. (1988: 219)

Não estaria o escritor português referindo-se a si mesmo? Estava, e a todos os outros grandes que escreveram e viveram, cada um a seu modo, as amarguras de seu tempo e de seu lugar. $\mathrm{O}$ fato que deve ser salientado, porém, é a antecedência crítica seniana em pensar as relações luso-brasileiras e apontar possíveis explicações para velhos problemas de incompreensão e desconhecimento. Os estudos senianos sobre o Brasil na perspectiva de um olhar português são, sem dúvida, um mergulho profundo na cultura brasileira e uma reflexão séria e abalizada sobre os entraves 
sócio-político-culturais que impedem que Portugal e Brasil realizem realmente o projeto da lusofonia.

Infelizmente, a contribuição de Jorge de Sena, esse intelectual português em terras brasileiras, permanece ainda silenciada entre nós, pois continua restrito o interesse pela cultura portuguesa no Brasil de hoje e, portanto, são esquecidos ou ignorados seus escritores e pensadores, ressalvados, é óbvio, certos espaços acadêmicos. No entanto, o que Sena desejava era simplesmente o reconhecimento da herança portuguesa como uma exigência para o Brasil melhor se compreender, alterando a sua realidade de injustiça, assim como Portugal deveria compreender o seu real lugar histórico em relação ao país de língua portuguesa do outro lado do Atlântico. Seu trabalho crítico-analítico demonstrou muito claramente que era questão vital (e ainda é...) a aproximação real entre os dois países, não só com o fortalecimento de uma cultura de língua portuguesa, como também de novas relações sócio-político-econômicas no mundo contemporâneo.

Homem de Letras, buscou, especialmente, mostrar aos portugueses o Brasil para além de imagens míticas e/ou turísticas e, para os brasileiros, a importância cultural de entender a literatura como um processo permanente de compreensão do que seu povo foi e é, com a discussão perspicaz de diferenças e possibilidades de diálogo. Projeto lúcido e empenhado que Jorge de Sena, diferente dos escritores-turistas, propôs e buscou realizar na sua obra crítica e literária.

\section{Bibliografia}

Impressa

Andrade, C.D. de. (1992). Poesia e prosa. Nova Aguilar. Rio de Janeiro;

Lisboa, E. (pref. e sel.). (1979). Versos e alguma prosa de Jorge de Sena. Arcádia e Moraes. Lisboa;

Lourenço, E. (1999). A nau de Ícaro: Seguido de imagem e miragem da lusofonia. Gradiva. Lisboa;

Matos, M. (1999). Podereis roubar-me tudo: Subsídios para uma antologia da presença de Camões na produção literária de Jorge de Sena. Em: G. Santos (org.). Jorge de Sena em rotas entrecruzadas. Cosmos. Lisboa;

Sena,J. de. (1971). Dialécticas teóricas da literatura. Edições 70. Lisboa;

Sena, J. de. (1986). Poesia I. Edições 70. Lisboa; Sena, J. de. (1988). Estudos de cultura e literatura brasileira. Edições 70, Lisboa;

Sena, J.de. (1999). Estudos de literatura portuguesa. Presença. Lisboa;

Williams, F.G. (1999). Jorge de Sena: Tradutor. Em: G. Santos (org.). Jorge de Sena em rotas entrecruzadas. Cosmos. Lisboa.

\section{Digital}

Euclidesite - Vida e obra de Euclides da Cunha. (s. d.). Biografia. Acedido a 21 de outubro de 2019, em: https://euclidesite.com.br/ biografia/. 